\title{
ESCALA DE AUTOEFICÁCIA ACADÊMICA PARA O ENSINO MÉDIO: BUSCA DE EVIDÊNCIAS PSICOMÉTRICAS
}

\author{
Soely Polydoro
}

Universidade Estadual de Campinas

\section{Daniela Couto Guerreiro Casanova \\ Universidade Nove de Julho}

\begin{abstract}
Resumo
Este artigo objetiva apresentar uma adaptação e a busca de evidências psicométricas de uma escala de autoeficácia acadêmica a ser utilizada com estudantes do ensino médio. Participaram 453 estudantes, com idade média de 15,93 (DP 1,2) anos, distribuídos entre as três séries do ensino médio. A escala adaptada, denominada Escala de Autoeficácia Acadêmica para o Ensino Médio, é composta por 16 itens e está organizada em três fatores: autoeficácia para aprender, autoeficácia para atuar na vida escolar e autoeficácia para decisão de carreira. Por meio de análise fatorial exploratória foi verificado $K M O=0,90$ e $56,57 \%$ da variância explicada. A consistência interna verificada foi 0,88 . Essa escala demonstrou boas condições para identificar a autoeficácia acadêmica dos estudantes do ensino médio.
\end{abstract}

Palavras-chave: autoeficácia; estudantes; ensino médio; motivação.

\section{ACADEMIC SELF-EFFICACY FOR HIGH SCHOOL SCALE: SEARCH FOR PSYCHOMETRICS EVIDENCE}

\begin{abstract}
This article aims to present the adaptation and the search for psychometrics evidence of an academic self-efficacy scale. High school students $(N=453)$ participated of the research (mean age 15.93; SD 1.2). The Academic Self-efficacy Scale for High School is an adapted scale composed of 16 items and organized into three factors: selfefficacy for learning, self-efficacy to act in school life, and self-efficacy for the career decision. Through exploratory factor analysis, a $\mathrm{KMO}=0.90$ was verified, and $56.57 \%$ of the variance was explained. The internal consistency was 0.88 . The scale demonstrated good conditions to identify academic self-efficacy of high school students.
\end{abstract}

Keywords: self-efficacy; students; high school; motivation.

\section{ESCALA DE AUTO-EFICACIA ACADÉMICA PARA SECUNDARIA: BÚSQUEDA DE PRUEBAS PSICOMÉTRICAS}

\begin{abstract}
Resumen
Este artículo presenta una adaptación y la búsqueda de pruebas psicométricas de una escala de auto-eficacia académica para su uso con estudiantes de secundaria. 453 estudiantes participaron, con una edad media de 15,93 (SD 1,2) años, repartidos entre los tres grados de la escuela secundaria. La escala adaptada, Ilamado escala Autoeficacia Académica para la Escuela Secundaria, consta de 16 artículos y está organizada en tres factores: la auto-eficacia para el aprendizaje, auto-eficacia para actuar en la vida escolar y la auto-eficacia para la toma carrera. A través del análisis factorial exploratorio se verificó $\mathrm{KMO}=0,90$ y $56,57 \%$ de la varianza explicada. La consistencia interna se comprobó 0,88. Esta escala demuestra buenas condiciones para identificar la auto-eficacia académica de los estudiantes de secundaria.

Palabras clave: auto-eficacia; estudiantes; escuela secundaria; motivación.
\end{abstract}




\section{INTRODUÇÃO}

Nos últimos anos, muito se tem discutido sobre o ensino médio. Há estudos que discutem a crise de identidade desse nível de ensino (Abramovay \& Castro, 2003), sua instabilidade político-pedagógica e as diversas reformas curriculares que o têm permeado (Zibas, Ferretti, \& Tartuce, 2006), entre outros temas. Parece haver certo consenso quando se considera que o ensino médio contribui para além da aprendizagem de conteúdos e de conhecimentos, ao colaborar para a formação ética, profissional e existencial dos estudantes que o frequentam (Abramovay \& Castro, 2003), ao intensificar as possibilidades de interação e convivência com outras pessoas, ao ampliar as experiências de vida e auxiliar na construção da história de vida de cada estudante (Abramovay \& Castro, 2003; Sposito, 2008; Teixeira, 2011). Tal formação pode culminar com a inserção dos estudantes no mundo do trabalho e/ou no ensino superior, mas não a garante, como também não assegura a relação teoria-prática com o conhecimento adquirido (Abramovay \& Castro, 2003; Sposito, 2008).

Sob o ponto de vista dos estudantes, alguns estudos ressaltam que eles parecem demonstrar confiança na escola como fonte de possibilidade para um futuro melhor (Sposito, 2008), como preparo para o mundo do trabalho e/ou para ingresso no ensino superior (Abramovay \& Castro, 2003). Outros elucidam as vivências escolares permeadas por dificuldades tanto de relacionamento quanto de participação em atividades ou projetos realizados (Zibas et al., 2006) e evidenciam falta de sentido relativa às ações realizadas pela escola (Sposito, 2008; Teixeira, 2011). Escutar os estudantes a fim de obter suas percepções sobre o ensino médio tem sido apontado como necessário para que se possa organizar esse nível de ensino, de modo a proporcionar uma formação com sentido cultural ao jovem brasileiro, com diversidade e equidade (Abramovay \& Castro, 2003; Sposito, 2008; Teixeira, 2011; Zibas et al., 2006).

Diante deste contexto, este artigo dedica-se à apresentação de um instrumento de autorrelato que pode auxiliar a obtenção das percepções de estudantes de ensino médio, mais especificamente sobre suas crenças de autoeficácia acadêmica, construto que tem demonstrado grande relevância para as vivências escolares e de aprendizagem (Azzi \& Polydoro, 2011; Azzi, Guerreiro-Casanova, \& Dantas, 2014; Zimmerman \& Schunk, 2003). Esta pesquisa teve como objetivo adaptar a escala Autoeficácia na Formação Superior (Polydoro \& Guerreiro-Casanova, 2010), de modo a possibilitar a sua utilização com estudantes do ensino médio, além de buscar evidências psicométricas da versão adaptada.

\section{Autoeficácia acadêmica: o construto e sua avaliação}

A motivação para aprender pode ser compreendida sob diversas perspectivas teóricas (Boruchovitch \& Bzuneck, 2010). Neste artigo, a motivação para aprender será analisada sob a perspectiva da Teoria Social Cognitiva 
(Bandura, 1997), considerando-se o construto autoeficácia acadêmica. Essa teoria assume como concepção de aprendizagem a necessidade de se desenvolver autocrenças de capacidades e competências autorregulatórias, de modo que o estudante possa autodirigir a própria aprendizagem (Azzi \& Polydoro, 2011; Azzi et al., 2014).

A autoeficácia acadêmica é definida como as crenças de alguém em sua capacidade de organizar e executar cursos de ações requeridos para produzir certas realizações relacionadas aos aspectos intelectuais e de aprendizagem (Bandura, 1993). Essas crenças constituem-se como um conceito mediador dos processos cognitivos, afetivos, seletivos e motivacionais, por meio dos quais esse conceito auxilia na regulação do comportamento do estudante frente ao aprender.

O estabelecimento de objetivos para si mesmo; a expectativa de se obter desempenho adequado ou não; a decisão sobre participar ou não de determinadas atividades escolares; a presença e a quantidade de estresse e de ansiedade experimentada pelos estudantes em relação às tarefas escolares são aspectos mediados pela percepção de autoeficácia acadêmica dos estudantes, de modo que estudantes com crenças de eficácia acadêmica mais fortes estabelecem cenários mais positivos para si mesmos, demonstram maior esforço, participação e engajamento em atividades do aprender, porque se sentem capazes de realizar com êxito tais tarefas (Bandura, 1993, 1997; Azzi et al., 2014). Faz-se necessário esclarecer que a crença de autoeficácia acadêmica não garante a habilidade necessária para a realização com êxito de determinada tarefa; no entanto, a presença dessa crença pode impulsionar o estudante a realizar ações que o levem ao desenvolvimento e à aprendizagem de tal habilidade (Azzi \& Polydoro, 2010). Este é um dos aspectos que tornam a crença de autoeficácia acadêmica tão importante para o aprender.

A crença de autoeficácia acadêmica é construída ao longo da vida do estudante, por meio de quatro fontes de informações: (1) experiência direta, por meio da qual as vivências de êxito na realização das atividades fornecem informações que são interpretadas como positivas e fortificam a percepção de autoeficácia acadêmica; (2) experiência vicária, situação em que o estudante pode, por meio da observação de modelos semelhantes a si próprio, aprender novas estratégias, bem como perceber que também possui as capacidades necessárias para determinada realização; (3) persuasão social, pois, quando o estudante é participante de um ambiente social que promove a percepção de que ele possui as capacidades para resolver tarefas difíceis, esse estudante despenderá mais esforço para resolver dadas situações. Contudo, é importante ressaltar que não basta ter "fé" na capacidade de alguém; quem visa persuadir e estimular outras pessoas a construir uma forte crença de autoeficácia deve arranjar situações de modo que elas possam ter sucesso, evitando colocá-las em conjunturas prematuras nas quais possam fracassar; e (4) estados físicos e 
emocionais, como sono e ansiedade, pois a maneira pela qual esses estados são interpretados pode desencadear um fraco julgamento da capacidade frente à resolução de determinada tarefa, sendo o contrário também verdadeiro (Bandura, 1993, 1997).

A crença de autoeficácia acadêmica não é estática, já que pode sofrer alterações durante as experiências escolares (Bandura, 1993, 1997), diferindo de uma série para outra (Azzi, Guerreiro-Casanova, \& Dantas, 2010) ou, até mesmo, no decorrer do ano letivo (Guerreiro-Casanova \& Polydoro, 2011b). Essa crença apresenta correlação significativa e positiva com o uso de estratégias de estudo e de aprendizagem, independentemente do turno que o aluno frequenta a escola ou da condição de exercer trabalho remunerado ou não (Azzi, GuerreiroCasanova, Dantas, \& Maciel, 2011). A percepção dos estudantes sobre as tarefas escolares como relevantes e interessantes influenciam os níveis de percepção de autoeficácia acadêmica (Zambom, Azzi, Polydoro, De Rose, \& GuerreiroCasanova, 2011). A família na qual o estudante está inserido também pode contribuir para alterações no julgamento da autoeficácia realizado pelos estudantes, pois a relação que os pais cultivam com seus filhos e a vida escolar dos mesmos parece influenciar a percepção de autoeficácia acadêmica dos estudantes, sendo mais importante do que o nível de ensino dos pais (GuerreiroCasanova, Dantas, \& Azzi, 2011).

Para a identificação da crença de autoeficácia acadêmica, sugere-se a utilização de escalas, desde que observadas algumas características inerentes ao constructo da autoeficácia, aliadas aos procedimentos de busca de evidências de validade de uma escala conforme as técnicas da psicometria (Bandura, 1997, 2006; Bong, 2006; Polydoro, Azzi, \& Vieira, 2010). O primeiro aspecto é relativo ao conteúdo exposto pelos itens, de modo que esse conteúdo reflita a definição do construto. Neste caso, é necessário alertar para o fato de que a percepção de autoeficácia é relativa ao julgamento sobre a própria capacidade, e não sobre a intencionalidade, não sobre a autoestima, não sobre o lócus de controle ou as expectativas de resultados. Para tanto, utilizar a expressão quanto eu sou capaz de, bem como redigir os itens no tempo verbal presente colocam-se como importantes recursos, a fim de se obter a percepção do estudante sobre sua própria capacidade (Bandura, 1997, 2006; Polydoro et al., 2010).

Dado que a autoeficácia é um construto relacionado a domínios de ações específicos, faz-se necessário garantir que os itens da escala sejam compatíveis com o domínio que se pretende investigar (Bong, 2006). Assim, para se obter informações sobre a autoeficácia acadêmica, ou seja, sobre o domínio acadêmico, é importante conhecer as tarefas que integram esse domínio e garantir que essas tarefas sejam representadas pelos itens da escala (Polydoro et al., 2010).

Dentro de cada domínio é possível considerar a dimensão generalidade, a qual se refere à amplitude do domínio que será contemplado na investigação. 
Conforme a generalidade representada em uma escala, podem-se encontrar diferentes informações explicativas para a autoeficácia acadêmica (Bandura, 1997, 2006; Bong, 2006; Polydoro et al., 2010). A especificidade do domínio a ser investigado é definida pelo pesquisador, coerentemente com o objetivo da pesquisa, de modo que se pode analisar o domínio acadêmico, por exemplo, contemplando os múltiplos aspectos que integram as atividades do aprender, como a participação no ambiente escolar, ou se pode investigar a autoeficácia para aprender matemática, contemplando apenas as tarefas necessárias para o aprender desta disciplina (Bong, 2006).

Além da dimensão generalidade, uma escala que vise mensurar a percepção de autoeficácia necessita proporcionar condições para analisar as dimensões: força e nível (Bandura, 1997, 2006; Bong, 2006; Polydoro et al., 2010). A dimensão força oferece meios para identificar a intensidade da crença do estudante. Por meio de respostas estruturadas em contínuo de 0 a 10 são obtidas a percepção e a intensidade da autoeficácia, de modo que, quanto mais alto é o número escolhido, mais intensa é a percepção de eficácia. A dimensão nível é relativa ao grau de dificuldade das tarefas que integram o domínio a ser investigado. Na prática, as inúmeras tarefas que compõem um domínio específico diferem-se entre si em níveis de dificuldades. Isso deve ser representado na escala, de modo a tornar possível a identificação da crença de eficácia frente às tarefas mais desafiadoras.

De acordo com as características específicas para a identificação da percepção da autoeficácia, Bandura (1990) elaborou, entre outras, a Multidimensional Scale of Perceived Self-efficacy (MSPSE), composta por 57 itens, distribuídos em nove domínios que visavam obter a compreensão sobre atividades e/ou vivências que traziam dificuldades aos estudantes. Após a utilização dessa escala em outros estudos, inclusive transculturais (Zimmermam, Bandura, \& Martinez-Pons, 1992; Choi, Fuqua, \& Griffin, 2001; Pastorelli et al., 2001), tal escala foi adaptada e passou a ser identificada como Children's SelfEfficacy Scale - CSFS (Bandura, 2006), sendo raros os estudos que descrevem a estrutura dos itens e as qualidades psicométricas das duas versões dessa escala (Choi et al., 2001). A CSFS (Bandura, 2006) é composta por 55 itens, em formato Likert de 0 (não sou confiante) a 100 (altamente confiante) pontos, distribuídos nas mesmas nove subescalas: autoeficácia para conseguir suporte social, autoeficácia para desempenho acadêmico, autoeficácia para aprendizagem autorregulada, autoeficácia para atividades extracurriculares e de lazer, autoeficácia regulatória, autoeficácia para atender às expectativas dos outros, autoeficácia social, autoeficácia assertiva e autoeficácia para conseguir suporte parental e comunitário.

Freitas (2011) realizou um estudo de adaptação e de busca de evidência da CSFS para a realidade brasileira. Esse estudo contou com a participação de 679 alunos matriculados em escolas públicas de Juiz de Fora, Minas Gerais, 
cursando entre o $6^{\circ}$ ano do ensino fundamental e o $3^{\circ}$ ano do ensino médio, com idade entre 10 e 26 anos. A versão da CSFS-BR de Freitas (2011) é formada por 54 itens (pois os itens "aprender ciências" e "aprender biologia", da escala original, foram unificados), com Alpha de Conbrach entre 0,67 (subescala autoeficácia para conseguir suporte social) e 0,87 (subescala autoeficácia para aprendizagem autorregulada), e variância observada entre 39,5\% (subescala autoeficácia para desempenho acadêmico) e 57\% (subescala autoeficácia para atender às expectativas dos outros).

Além da escala adaptada por Freitas (2011), foram localizadas as seguintes escalas sobre autoeficácia relativas ao domínio educacional desenvolvidas por pesquisadores brasileiros: Escala de Autoeficácia Acadêmica Percebida (Sá, 2006); Escala de Autoeficácia para Alunos do Ensino Fundamental (Martinelli, Bartholomeu, Caliatto, \& Sassi, 2009) e Escala de Autoeficácia na Formação Superior (Polydoro \& Guerreiro-Casanova, 2010), as quais serão apresentadas a seguir.

A Escala de Autoeficácia Acadêmica Percebida (Sá, 2006) foi desenvolvida para obter percepções de estudantes universitários, sendo composta por 20 itens, com resposta em formato Likert de 0 a 100 pontos. É organizada em quatro fatores que explicam $58 \%$ da variância: autoeficácia acadêmica percebida para lidar com tarefas que requeiram exposição de necessidades acadêmicas intrapessoais; autoeficácia acadêmica percebida para lidar com tarefas cognitivas; autoeficácia acadêmica percebida para lidar com tarefas que exijam trocas interpessoais; e autoeficácia acadêmica percebida para lidar com tarefas de organização de tempo e de prioridades. Essa escala apresentou consistência interna adequada ( $\mu=0,902$; Spearman-Brown).

A Escala de Autoeficácia para Alunos do Ensino Fundamental (Martinelli et al., 2009) foi desenvolvida para crianças. É composta por 20 itens, com possibilidade de respostas de 0 (nada capaz) a 4 (muito capaz), estando organizada em dois fatores: autoeficácia para o estudo (Alpha de Cronbach de 0,79 ) e autoeficácia para o desempenho acadêmico (Alpha de Cronbach de 0,75), explicando $35,17 \%$ da variância.

A Escala de Autoeficácia na Formação Superior (Polydoro \& GuerreiroCasanova, 2010) foi desenvolvida para estudantes universitários, sendo composta por 34 itens, com possibilidades de resposta de 1 (pouco capaz) a 10 (muito capaz). Está organizada em cinco fatores: autoeficácia acadêmica; autoeficácia na regulação da formação; autoeficácia para ações proativas; autoeficácia para interação social; e autoeficácia para gestão acadêmica. Essa escala apresentou consistência interna de 0,94 e explicou 56,68\% da variância sobre a autoeficácia na formação superior.

Considerando as peculiaridades do ensino médio e as possibilidades de contribuição que o conhecimento sobre a percepção da autoeficácia acadêmica dos estudantes pode trazer em benefício da prática educativa, acredita-se que 
esta pesquisa mostra-se relevante para o aprimoramento sobre a compreensão do cenário aqui brevemente discutido. Isto porque um instrumento nacional específico para a obtenção da percepção da autoeficácia acadêmica dos estudantes de ensino médio pode contribuir para a obtenção de informações sobre as percepções de autoeficácia acadêmica, as quais poderiam orientar o desenvolvimento de práticas educativas específicas para o ensino médio.

\section{MÉTODO}

\section{Participantes}

Participaram deste estudo 453 estudantes do ensino médio, provenientes de nove escolas públicas estaduais, localizadas na região metropolitana e no interior do Estado de São Paulo. Destes participantes, $288(63,6 \%)$ eram do sexo feminino. Em relação à idade, a amostra foi composta por estudantes entre $14 \mathrm{e}$ 24 anos, com idade média de 15,93 anos ( $D P=1,2$ anos). Quanto às séries, 155 $(34,4 \%)$ estudantes cursavam a $1^{\text {a }}$ série, $163(35,7 \%)$ estudantes cursavam a $2^{\text {a }}$ série e $135(29,9 \%)$ estudantes cursavam a $3^{\text {a }}$ série do ensino médio. Em relação aos turnos de estudo, $238(52,5 \%)$ estudantes frequentavam a escola no turno matutino, 181 (40\%) no turno noturno e 34 (7,5\%) no turno vespertino. A maioria dos estudantes desta amostra pretende concluir o ensino médio $(99,8 \%$, $n=449)$ e ingressar no ensino superior $(96,6 \%, n=427)$. Em relação à condição de exercer atividade de trabalho remunerado, 134 (29,8\%) estudantes declararam-se trabalhadores.

\section{Instrumento}

A escala aqui estudada é uma adaptação da escala de Autoeficácia na Formação Superior - AEFS (Polydoro \& Guerreiro-Casanova, 2010). Essa escala original constitui-se como um instrumento de autorrelato que objetiva identificar a autoeficácia de estudantes universitários para organizar e executar cursos de ações requeridos para produzir certas realizações referentes aos aspectos compreendidos pelas tarefas acadêmicas pertinentes ao ensino superior. É composta por 34 itens, em formato Likert de 1 (pouco capaz) a 10 (muito capaz), organizados em dimensões, conforme pode ser observado na Tabela 1. 
Tabela 1.

Dimensões e Dados Psicométricos da Escala AEFS (Polydoro \& GuerreiroCasanova, 2010)

\begin{tabular}{|c|c|c|}
\hline $\begin{array}{l}\text { Dimensão } \\
\text { da } \\
\text { autoeficácia }\end{array}$ & Construto investigado & Dados psicométricos* \\
\hline Acadêmica & $\begin{array}{c}\text { Avalia a percepção dos estudantes } \\
\text { sobre a confiança na capacidade de } \\
\text { aprender, demonstrar e aplicar o } \\
\text { conteúdo do curso. }\end{array}$ & $\begin{array}{l}\text { No de itens }=9 \\
\text { Variância: } 37,87 \% \\
\qquad a=0,88\end{array}$ \\
\hline $\begin{array}{l}\text { Regulação } \\
\text { da formação }\end{array}$ & $\begin{array}{c}\text { Reflete a percepção na confiança na } \\
\text { própria capacidade de estabelecer } \\
\text { metas, fazer escolhas, planejar e } \\
\text { autorregular suas ações no processo } \\
\text { de formação e desenvolvimento de } \\
\text { carreira. }\end{array}$ & $\begin{array}{c}\text { No de itens }=7 \\
\text { Variância: } 6,15 \% \\
\qquad a=0,88\end{array}$ \\
\hline $\begin{array}{c}\text { Ações } \\
\text { proativas }\end{array}$ & $\begin{array}{c}\text { Destina-se à identificação da } \\
\text { confiança percebida na capacidade de } \\
\text { aproveitar as oportunidades de } \\
\text { formação, atualizar os conhecimentos } \\
\text { e promover melhorias institucionais. }\end{array}$ & $\begin{array}{c}\text { No de itens }=7 \\
\text { Variância: } 4,26 \% \\
\quad a=0,85\end{array}$ \\
\hline $\begin{array}{c}\text { Interação } \\
\text { Social }\end{array}$ & $\begin{array}{c}\text { Avalia a percepção dos estudantes } \\
\text { sobre a confiança na capacidade de } \\
\text { relacionar-se com os colegas e } \\
\text { professores com fins acadêmicos e } \\
\text { sociais. }\end{array}$ & $\begin{array}{c}\text { No de itens }=7 \\
\text { Variância: } 4,85 \% \\
\quad a=0,80\end{array}$ \\
\hline $\begin{array}{c}\text { Gestão } \\
\text { acadêmica }\end{array}$ & $\begin{array}{c}\text { Refere-se a confiança percebida na } \\
\text { capacidade de envolver-se, planejar e } \\
\text { cumprir prazos em relação às } \\
\text { atividades acadêmicas. }\end{array}$ & $\begin{array}{l}\text { No de itens }=4 \\
\text { Variância: } 3,53 \% \\
\qquad a=0,80\end{array}$ \\
\hline
\end{tabular}

Nota. * Número de itens na escala, variância explicada e valores de alfa de Cronbach (a).

A escala AEFS, como um todo, obteve consistência interna entendida como favorável (Alpha de Conbrach 0,94), demonstrando condições para explicar $56,68 \%$ da autoeficácia na formação superior (Polydoro \& Guerreiro-Casanova, 2010). Tem sido utilizada em outras pesquisas (Guerreiro-Casanova \& Polydoro, 2011a, 2011b), também apresentando qualidades psicométricas adequadas. Essa escala apresenta condições de identificar a percepção da autoeficácia de acordo com as orientações de Bandura (2006), bem como de obter informações sobre diversas tarefas acadêmicas pertinentes ao ensino superior, contemplando a amplitude do domínio relativo a este nível de ensino. 
A escala de Autoeficácia na Formação Superior também foi adaptada para o contexto acadêmico de Portugal (Vieira, Caires, \& Polydoro, 2011), em que, após estudos de adaptações e de busca de validade, passou a contar com 20 itens, em formato Likert de 6 pontos ( 1 para nada confiante e 6 para muito confiante), organizados em três fatores: autoeficácia acadêmica (Alpha de Conbrach 0,90), autoeficácia na regulação da formação (Alpha de Conbrach 0,90 ) e autoeficácia na interação social (Alpha de Conbrach 0,86). Diante das condições favoráveis verificadas na AEFS em que foi analisada, decidiu-se adaptar essa escala para o domínio acadêmico relativo às vivências dos estudantes do ensino médio.

O processo de adaptação da AEFS para o ensino médio iniciou-se com o ajuste da linguagem e do contexto dos itens, para que os mesmos pudessem ser compreendidos pelos estudantes do referido nível de ensino. Com o intuito de garantir que o maior número possível de tarefas relativas às vivências acadêmicas e escolares estivesse presente na nova escala tal processo considerou os 52 itens elaborados para a primeira versão da AEFS (que, após estudo de busca de evidências, apresentou 34 itens, como pôde ser observado na Tabela 1). Após análise qualitativa sobre os conteúdos desses 52 itens, decidiu-se excluir os itens que demonstravam conteúdos semelhantes. Assim, obteve-se uma primeira versão da escala de autoeficácia acadêmica dedicada ao ensino médio, com 31 itens, a qual foi submetida à análise de um juiz com domínio da Teoria Social Cognitiva e da psicometria.

Seguindo sugestão do juiz, as possibilidades de resposta foram reestruturadas, passando à escala Likert de 7 pontos (1 para pouco capaz e 7 para muito capaz). Tal decisão foi decorrente do fato de que essa escala seria utilizada em conjunto com outros instrumentos em uma pesquisa sobre motivação escolar (Zambom et al., 2011), os quais apresentavam possibilidades de resposta em até 7 pontos.

Essa versão da escala foi apresentada para dez estudantes de ensino médio de diferentes escolas, aos quais foi solicitada opinião sobre a clareza e a contextualização dos itens. Pequenos ajustes de texto foram realizados após esse procedimento, mas não houve alteração na estrutura da escala, a qual foi aplicada e submetida aos estudos de busca de evidências de validade e consistência, cujos resultados serão apresentados a seguir.

\section{Procedimentos}

Este estudo iniciou-se após a autorização do Comitê de Ética em Pesquisa e das diretoras das escolas participantes. Em dias previamente agendados, os pesquisadores foram às salas de aula e explicaram os objetivos da pesquisa aos estudantes. Aos que demonstraram interesse em participar da pesquisa, foi entregue o Termo de Consentimento Livre e Esclarecido, no qual constavam os objetivos da pesquisa, bem como as informações de que a participação seria 
voluntária, não traria bônus nem ônus aos participantes e que as informações obtidas seriam sigilosas. Os estudantes menores de 18 anos levaram os termos de consentimento para casa, visando obter autorização dos pais e/ou responsáveis para a participação da pesquisa. Os estudantes maiores de 18 anos assinaram a própria autorização.

Também em dia previamente combinado os pesquisadores voltaram para coletar os dados junto aos estudantes que portavam o termo de consentimento assinado. A coleta foi realizada em sala de aula, durante as aulas de português, de forma coletiva e com duração média de 30 minutos. Um pesquisador estava presente no momento da coleta e forneceu as orientações necessárias para o preenchimento do instrumento.

\section{RESULTADOS}

O procedimento de análise fatorial exploratória, por análise de componentes principais e rotação varimax, foi realizado por meio do programa SPSS (versão 17). Por meio de critérios aplicados gradativamente até garantir bons índices psicométricos associados à coerência conceitual da escala, o número de fatores diminuiu de cinco, presentes na escala original, para três na versão destinada ao ensino médio. Foram excluídos 13 itens, com carga fatorial menor que 0,50 . No entanto, três itens com cargas entre 0,33 e 0,46 foram mantidos por serem considerados importantes para a amplitude conceitual da escala. Observou-se que a retirada de outro item resultaria um mínimo aumento do Alpha de Cronbach da escala, de modo que se julgou pertinente manter os 16 itens e garantir a generalidade sobre o domínio. Na Tabela 2 podem-se observar as dimensões, as respectivas cargas fatoriais, além de outros dados psicométricos que integram a versão final da escala, que passou a ser denominada Escala de Autoeficácia Acadêmica para o Ensino Médio (AAEM). 
Tabela 2.

Dimensões e Dados da Escala Autoeficácia Acadêmica para o Ensino Médio

\begin{tabular}{|c|c|c|c|}
\hline Dimensões & Destina-se a verificar & Dados & Itens \\
\hline $\begin{array}{c}\text { Autoeficáci } \\
\text { a para } \\
\text { Aprender }\end{array}$ & $\begin{array}{c}\text { Confiança percebida na } \\
\text { capacidade de mobilizar } \\
\text { esforços para se envolver } \\
\text { nas atividades escolares } \\
\text { considerando os aspectos } \\
\text { cognitivos, motivacionais e } \\
\text { comportamentais } \\
\text { pertinentes ao processo de } \\
\text { aprender e ao desempenho } \\
\text { acadêmico. }\end{array}$ & $\begin{array}{c}\text { Variância } \\
\text { explicada: } \\
24,56 \% \\
\text { Cargas } \\
\text { fatoriais entre } \\
0,49 \text { e } 0,73\end{array}$ & $\begin{array}{c}\text { Exemplo de item: } \\
\text { Quanto eu sou capaz } \\
\text { de motivar-me para } \\
\text { fazer as } \\
\text { atividades/tarefas } \\
\text { relacionadas a esta } \\
\text { disciplina? }\end{array}$ \\
\hline $\begin{array}{l}\text { Autoeficáci } \\
\text { a para } \\
\text { atuar na } \\
\text { vida } \\
\text { escolar }\end{array}$ & $\begin{array}{c}\text { Confiança percebida na } \\
\text { capacidade de atuar na } \\
\text { vida escolar, considerando } \\
\text { o envolvimento } \\
\text { colaborativo com os pares } \\
\text { e a escola/instituição. }\end{array}$ & $\begin{array}{c}\text { Variância } \\
\text { explicada: } \\
17,61 \% \\
\text { Cargas } \\
\text { fatoriais entre } \\
0,71 \text { e } 0,80\end{array}$ & $\begin{array}{c}\text { Itens: } 12,14,15,16 \\
\text { Exemplo de item: } \\
\text { Quanto eu sou capaz } \\
\text { de contribuir com ideias } \\
\text { para a melhoria da } \\
\text { minha escola? }\end{array}$ \\
\hline $\begin{array}{l}\text { Autoeficáci } \\
\text { a para } \\
\text { decisão de } \\
\text { carreira }\end{array}$ & $\begin{array}{l}\text { Confiança percebida na } \\
\text { capacidade de buscar } \\
\text { informações e planejar } \\
\text { ações relevantes para a } \\
\text { decisão de carreira. }\end{array}$ & $\begin{array}{c}\text { Variância } \\
\text { explicada: } \\
14,39 \% \\
\text { Cargas } \\
\text { fatoriais entre } \\
0,56 \text { e } 0,70\end{array}$ & $\begin{array}{c}\text { Itens: } 3,4,10,11 \\
\text { Exemplo de item: } \\
\text { Quanto eu sou capaz } \\
\text { de definir com } \\
\text { segurança o que } \\
\text { pretendo seguir como } \\
\text { profissão dentre as } \\
\text { diversas possibilidades } \\
\text { de atuação profissional } \\
\text { que existem? }\end{array}$ \\
\hline
\end{tabular}

A escala, considerada em sua totalidade com 16 itens, demonstrou bons índices: $K M O$ de 0,90 e variância explicada de 56,57\%. Praticamente a totalidade dos itens apresentou correlação significativa, positiva e moderada ( $>0,40$ e $\leq$ $0,70)$ com o score total da escala. A exceção foi o item Quanto eu sou capaz de pedir ajuda aos colegas nas atividades desta disciplina, que demonstrou correlação significativa, positiva e fraca $(0,15)$ com o score total da escala. Esclarece-se que este foi um dos itens que permaneceram na escala, devido a questões conceituais, mesmo tendo demonstrado carga fatorial menor que 0,50. Todos os itens apresentaram correlações positivas com os outros itens que integram os fatores em que se agruparam.

Os oito itens da dimensão autoeficácia para aprender apresentaram correlações significativas e positivas entre si, consideradas entre fracas e moderadas $(\geq 0,28$ e $\leq 0,62)$. Dos quatro itens da dimensão autoeficácia para 
atuar na vida escolar, três itens apresentaram correlações significativas e positivas entre fraca e moderada $(\geq 0,26$ e $\leq 0,66)$, sendo que o item Quanto eu sou capaz de pedir ajuda aos colegas nas atividades desta disciplina só apresentou correlação significativa, positiva e fraca com o item Quanto eu sou capaz de trabalhar em grupo, e tal item não apresentou correlação significativa com os outros dois itens dessa dimensão. Os quatro itens da dimensão autoeficácia para decisão de carreira demonstraram correlação positiva e moderada ( $\geq 0,49$ e $\leq 0,60$ ) entre si. A classificação da intensidade das correlações seguiu o critério de Dancey e Reidy (2006).

Os 16 itens da escala apresentaram média descritiva que pode ser considerada moderada, oscilando entre 4,35 e 5,93. Como exemplo, cita-se o item Quanto eu sou capaz de estudar quando existem outras coisas para fazer, o qual demonstrou a menor média $(M=4,35, D P=1,79)$, e o item Quanto eu sou capaz de planejar ações para atingir meus objetivos profissionais, com a maior média $(M=5,93, D P=1,31)$. Os desvios padrões oscilaram entre 1,31 , para 0 item Quanto eu sou capaz de planejar ações para atingir meus objetivos profissionais, e 1,83, para o item Quanto eu sou capaz de contribuir com ideias para a melhoria da minha escola.

\section{DISCUSSÃO}

Este estudo preliminar da escala AAEM demonstrou boas evidências de validade, conforme resultados expostos. Apesar de não ter sido mantida a organização fatorial semelhante à escala original AEFS (Polydoro \& GuerreiroCasanova, 2010), como já esperado, pode-se destacar que a nova organização fatorial verificada na escala específica para o ensino médio é compatível com a conceituação teórica da autoeficácia acadêmica, a qual contempla as múltiplas tarefas deste domínio, que neste estudo considera os aspectos relacionados ao aprender, ao atuar socialmente e à decisão de carreira.

Tal delimitação de domínio parece ser indicada à obtenção de crenças de autoeficácia acadêmica compatíveis com a compreensão de que o ensino médio proporciona formação multidimensional, contemplando além da aquisição de conteúdos, a formação social, de orientação ao ingresso no mundo do trabalho (Abramovay \& Castro, 2003; Sposito, 2008) e de ativação de capacidades autorreguladoras (Azzi \& Polydoro, 2011).

Por meio da dimensão autoeficácia para aprender, pode-se captar o julgamento dos estudantes relativo às próprias capacidades necessárias para aprenderem os conteúdos ensinados no ensino médio, bem como aos requisitos para atingirem o objetivo de consolidar conhecimentos. Pela dimensão autoeficácia para atuação na vida escolar, é possível obter a percepção dos estudantes sobre as próprias capacidades necessárias para realizarem tarefas relativas à atuação e à participação efetiva nas vivências escolares, 
imprescindíveis para que os estudantes possam exercer o protagonismo juvenil e o desenvolvimento de formação social. E, finalmente, a dimensão autoeficácia para a decisão de carreira, na qual os estudantes demonstram as percepções sobre as próprias capacidades relativas ao planejamento de carreira, é compatível com o objetivo de preparo para o trabalho e/ou para o prosseguimento dos estudos.

Por meio dos resultados obtidos pela análise descritiva (médias entre 4,35 e 5,93 e desvio padrão entre 1,32 e 1,83), percebe-se a necessidade de se investigar mais as condições de discriminação dos itens que integram esta escala. Uma possibilidade para tal fim seria ampliar a estrutura de resposta, passando de formato Likert de 7 pontos para uma estrutura de 10 pontos (Bandura, 1997, 2006). Acredita-se que uma estrutura de resposta em formato de 10 pontos seria mais apropriada, visto que esses estudantes habitualmente lidam com um intervalo de 10 pontos durante os processos de avaliação (Bandura, 1997, 2006; Bong, 2006).

Quando comparada a outras escalas de autoeficácia acadêmica disponíveis para a realidade brasileira, como a escala de autoeficácia para alunos do ensino fundamental (Martinelli et al., 2009) e a CSFS-BR (Freitas, 2011), pode-se comentar que a escala de Autoeficácia Acadêmica para o Ensino Médio (AAEM) demonstra a vantagem de contemplar a generalidade das vivências escolares desse nível de ensino. Isto porque tal escala apresenta condições de verificar a percepção de autoeficácia relativa às tarefas do aprender, da atuação social e da decisão de carreira, de modo compatível com o entendimento de que o ensino médio deve focalizar a formação oferecida para além da aquisição de conteúdos, ou seja, uma formação que contemple a diversidade da juventude brasileira, com possibilidades de ampliação de interações sociais e de experiências de vida, integrando a formação ética, profissional e existencial com a construção do saber (Abramovay \& Castro, 2003; Sposito, 2008; Teixeira, 2011).

A escala de Martinelli et al. (2009) foi devidamente elaborada para identificar a percepção de autoeficácia acadêmica de alunos do ensino fundamental. Já a escala adaptada por Freitas (2011), além de ser oriunda de outra cultura, tenta verificar a crença de autoeficácia acadêmica de alunos do ensino fundamental e do ensino médio, o que pode levar ao questionamento sobre as semelhanças e as diferenças entre esses dois níveis de ensino, tanto em relação a seus objetivos de formação quanto em relação à constituição pessoal dos diversos estudantes e suas características compatíveis com as respectivas faixas etárias.

Além das propriedades psicométricas verificadas, a escala de Autoeficácia Acadêmica para o Ensino Médio (AAEM) demonstrou condições de proporcionar as vantagens oferecidas pelos instrumentos de autorrelato. Entre essas vantagens destacam-se a possibilidade de realização de pesquisa com grande número de estudantes participantes, de modo anônimo ou não, dependendo do 
delineamento da pesquisa; o rápido tempo destinado à coleta de dados, com coleta realizada aproximadamente em 30 minutos; a uniformização dos procedimentos de pesquisa, a qual possibilita a comparação e a análise de dados; além de evitar que o pesquisador precise interpretar o que o participante respondeu, contribuindo para prevenir o julgamento de valor sobre a opinião dos participantes (Cozby, 2003).

Como ressaltado na seção Procedimentos, este estudo foi realizado em aulas de português, tendo sido solicitado que os estudantes respondessem esta escala considerando o contexto dessas aulas. Tal decisão foi decorrente do contexto em que este estudo de evidência esteve inserido, mas essa escala pode ser aplicada para se obter a percepção dos estudantes sobre autoeficácia acadêmica relativa a outras disciplinas ou sobre as vivências do ensino médio como um todo.

Outra possibilidade de aplicação é relativa à decisão de se utilizar a escala como um todo (com os três fatores) ou apenas o fator que se julgar mais adequado ao objetivo de estudo. Por exemplo, se a crença na capacidade de mobilizar esforços para se envolver nas atividades escolares for um objetivo de pesquisa ou de intervenção, pode-se usar apenas o fator Autoeficácia para Aprender. Porém, se o desejado for verificar o quanto o estudante se percebe capaz de exercer o protagonismo juvenil, pode-se utilizar o fator Autoeficácia para Atuar na Vida Escolar. E, por fim, se o objetivo de pesquisa estiver relacionado a aspectos de decisão de carreira, pode-se aplicar apenas o fator Autoeficácia para Decisão de Carreira.

Ressalta-se que, apesar das adequadas evidências psicométricas verificadas, tais resultados constituem-se como iniciais e inconclusivos, de modo que as evidências de validade aqui encontradas devem ser consideradas apenas para este estudo. Isto porque este estudo realizou análise de componentes principais, a qual "preocupa-se somente em determinar que componentes lineares existem dentro do dados" (Field, 2009, p.562) e difere da técnica utilizada para as comunalidades realizada na análise fatorial. Embora Field (2009) comente que a diferença entre a análise de componentes principais e a análise fatorial seja relativa principalmente aos cálculos, tal aspecto deve ser considerado em estudos futuros. Além disso, deve-se questionar também a organização dos itens em seus respectivos componentes fatoriais, dada a diferença de quantidade de itens entre os fatores aqui encontrados. Diante disso, tem-se a intenção de realizar novos estudos de busca de evidências de validade de conteúdo, de critério e de construto da escala de Autoeficácia Acadêmica para - Ensino Médio (AAEM). Para tanto, pretende-se ampliar a amostra e sua diversidade, bem como readequar os itens que foram eliminados neste estudo e reaplicá-los em uma amostra de validação cruzada, a fim de verificar a adequação dessa escala para identificar o construto pretendido. 
Acredita-se que essa escala tenha condição de captar a percepção da autoeficácia acadêmica dos estudantes de ensino médio. Tal valia vai além da possibilidade de mensuração, pois pode auxiliar o desenvolvimento dos conhecimentos sobre autoeficácia acadêmica e suas possibilidades explicativas e/ou preditivas em relação ao aprender, ainda insuficientes na academia brasileira, visto que o grande corpo de evidências sobre autoeficácia acadêmica foi desenvolvido em pesquisas internacionais. A escala AAEM também pode auxiliar no que corresponde a compreender mais o estudante e as características da juventude que atualmente frequenta o ensino médio, sendo mais uma possibilidade de se escutar os estudantes, a fim de ampliar o entendimento que especialistas de diversas áreas têm sobre eles.

Com a ciência de que a percepção de autoeficácia acadêmica pode ser fortalecida e desenvolvida ao longo da vida e que, para isso, a cada novo desafio escolar o estudante necessita de apoio e auxílio para atingir os objetivos acadêmicos e de formação (Azzi \& Polydoro, 2011), comenta-se aqui a viabilidade da escala de Autoeficácia Acadêmica para o Ensino Médio como um meio de identificação da intensidade das crenças de autoeficácia acadêmica dos estudantes, o que pode auxiliar ações de intervenção que visem fortalecer essa crença, como meio de ampliar as condições de aprendizagem. Diante disso, essa escala pode ser um relevante instrumento de contribuição para diminuir a crise de identidade do ensino médio, colaborando para se obter uma escola mais inclusiva, que contemple as diversidades da juventude brasileira, mas que também busque equidade em suas ações político-pedagógicas.

\section{REFERÊNCIAS}

Abramovay, M., \& Castro, M. C. (Orgs.). (2003). Ensino médio: múltiplas vozes. Brasília: UNESCO, MEC.

Azzi, R. G., Guerreiro-Casanova, D. C., \& Dantas, M. A. (2010). Autoeficácia acadêmica: possibilidade para refletir sobre o ensino médio. Eccos Revista Científica, 12(1), 51-67.

Azzi, R. G., Guerreiro-Casanova, D. C., \& Dantas, M. A. (2014). Autoeficácia acadêmica: percepções de estudantes brasileiros. In R. G. Azzi, \& D.A. Vieira (Org.). Crenças de eficácia em contexto educativo (pp. 67-83). São Paulo: Casa do Psicólogo.

Azzi, R. G., \& Polydoro, S. A. J. (2010). O papel da autoeficácia e autorregulação no processo motivacional. In E. Boruchovitch, J. A. Bzuneck, \& S. E. R. Guimarães (Org.) Motivação para aprender: aplicações no contexto educativo (pp. 126-144). Rio de Janeiro: Ed. Vozes. 
Azzi, R. G., \& Polydoro, S. A. J. (2011). Contribuições da Teoria Social Cognitiva de Albert Bandura ao contexto educativo. In R. G. Azzi, \& M. H.T.A. Gianfaldoni (Orgs.). Psicologia e Educação (pp. 177-198). (Série ABEP Formação). São Paulo: Casa do Psicólogo.

Azzi, R. G., Guerreiro-Casanova, D. C., Dantas, M. A., \& Maciel, A. C. (2011, July). Academic self-efficacy and learning and study strategies: Brazilian students' perceptions. Exposed in the 15th Biennial of the international study association on teachers and teaching, Braga, University of Minho, Portugal.

Bandura, A. (1990). Multidimensional scales of perceived self-efficacy. Stanford, CA: Stanford University.

Bandura, A. (1993). Perceived self-efficacy in cognitive development and functioning. Educational Psychologist, 28(2), 117-148. doi: 10.1207/s15326985ep2802_3

Bandura, A. (1997). Self-efficacy: the exercise of control. New York: W. H. Freeman.

Bandura, A. (2006). Adolescent development from an agentic perspective. In F. Pajares, \& T. Urdan. Self-efficay beliefs of adolescents (pp. 1-43). Connecticut: Information Age Publishing.

Bong, M. (2006). Asking the right question: how confident are you that you could successfully perform these tasks? In Pajares, F., \& Urdan, T. Self-efficay beliefs of adolescents (pp.287-305). USA: Information Age Publishing.

Boruchovitch, E., \& Bzuneck, J. A. (2010). Motivação para aprender no Brasil: estado da arte e caminhos futuros. In E. Boruchovitch, J. A. Bzuneck, \& S. E. R. Guimarães (Orgs.). Motivação para aprender: aplicações no contexto educativo (pp. 231-250). Petrópolis: Vozes.

Choi, N., Fuqua, D. R., \& Griffin, B. W. (2001). Exploratory analysis of the structure of scores from the multidimensional scales of perceived selfefficacy. Educational and Psychological Measurement, 61(3), 475-489. doi: $10.1177 / 00131640121971338$

Cozby, P. C. (2003). Métodos de pesquisa em ciências do comportamento (P. I. C. Gomide, \& E. S. J. O. Otta, Trads.). São Paulo: Atlas.

Dancey, C. P., \& Reidy, J. (2006). Estatística sem matemática para a psicologia: usando SPSS para Windows. Porto Alegre: Artmed.

Field, A. (2009). Descobrindo a estatística usando o SPSS. Porto Alegre: Artmed. 
Freitas, M. F. R. L. (2011). Autoeficácia: evidências de validade de uma medida e seu papel moderador no desenvolvimento de dotação e talento. Dissertação de Mestrado, Universidade Federal de Juiz de Fora, Minas Gerais.

Guerreiro-Casanova, D. C., Dantas, M. A., \& Azzi, R. G. (2011). Autoeficácia de alunos do ensino médio e nível de escolaridade dos pais. Estudos Interdisciplinares em Psicologia, 2(1), 36-55. doi: 10.1590/21753539/2014/0183760

Guerreiro-Casanova, D. C., \& Polydoro, S. A. J. (2011a). Autoeficácia e integração ao ensino superior: um estudo com estudantes de primeiro ano. Psicologia: Teoria e Prática, 13(1), 75-88.

Guerreiro-Casanova, D. C, \& Polydoro, S. A. J. (2011b). Autoeficácia na formação superior: percepções durante o primeiro ano de graduação. Psicologia: Ciência e profissão, 31(1), 50-65. doi: 10.1590/S141498932011000100006

Martinelli, S. C., Bartholomeu, D., Caliatto, S. G., \& Sassi, A. de G. (2009). Children's self-efficacy scale: initial psychometric studies. Journal of Psychoeducational Assessment, 27, 145-156. doi: $10.1177 / 0734282908325551$

Pastorelli, C., Caprara, G. C., Barbaranelli, C., Rola, J., Rozsa, S., \& Bandura, A. (2001). The structure of children's perceived self-efficacy: a cross-national study. European Journal of Psychological Assessment, 17(2), 87-97. doi: 10.1027//1015-5759.17.2.87

Perez, E. R., \& Delgado, M. F. (2006). Inventario de autoeficacia para el estudio: desarrollo y validación inicial. Avaliação Psicológica, 5(2), 135-143.

Polydoro, S. A. J., Azzi, R. G., \& Vieira, D. (2010). Orientações de construção e aplicações de escalas na avaliação de crenças de autoeficácia. In A. A. A. Santos, E. Boruchovith, E. Nascimento, \& F. F. Sisto (Orgs.). Perspectivas em avaliação psicológica (pp. 189-210). São Paulo: Casa do Psicólogo.

Polydoro, S. A. J., \& Guerreiro-Casanova, D. C. (2010). Escala de Autoeficácia na Formação Superior: construção e estudo de validação. Avaliação Psicológica, 9(2), 267-278.

Sá, A. P. (2006). Propriedades psicométricas de uma escala de auto-eficácia acadêmica e suas relações com desempenho estudantil e interação social. Revista brasileira de terapias cognitivas, 2(2), 61-72.

Sposito, M. P. (2008). Algumas reflexões e muitas indagações sobre as relações entre juventude e escola no Brasil. In H. W. Abramo, \& P. P. M. Branco (Orgs.). Retratos da Juventude Brasileira, Análises de uma pesquisa nacional. (pp. 87-127). São Paulo: Editora Fundação Perseu Abramo. 
Teixeira, M. L.T. (2011). Juventude, exclusão e processos educativos. In Azzi, R. G., \& M. H.T.A.Gianfaldoni (Orgs.). Psicologia e Educação. (p. 239-253). (Série ABEP Formação). São Paulo: Casa do Psicólogo.

Vieira, D., Caires, S., \& Polydoro, S. A. J. (2011, Julho). Escala de autoeficácia na formação superior (AEFS): análise factorial confirmatória. VIII Congresso Iberoamericano de Avaliação e XV Conferência Internacional Avaliação Psicológica: Formas e Contextos, Lisboa.

Zambom, M. P., Azzi, R. G., Polydoro, S. A. J., De Rose, T. M., \& GuerreiroCasanova, D. C. (2011, jun.). Relations entre perceptions de la structure de la classe, auto-efficacité, buts d'accomplissement, stratégies d'apprentissage et performance dans un groupe de brésiliens. Congrès 2011 de I'Association Francophone Internationale de Recherche Scientifique en Education (p. 147-151), UNESCO. Paris, França.

Zibas, D. M. L., Ferretti, C. J., \& Tartuce, G. L. B. P. (2006). Micropolítica escolar e estratégias para o desenvolvimento do protagonismo juvenil. Cadernos de pesquisa, 36(127), 51-58. doi: 10.1590/S0100-15742006000100004

Zimmerman, B. J., Bandura, A., \& Martinez-Pons, M. (1992). Self-motivation for academic attainment: the role of self-efficacy beliefs and personal goal settings. American Education Research Journal, 29(3), 663-676. doi: $10.3102 / 00028312029003663$

Zimmerman, B. J., \& Schunk, D. (2003). Albert Bandura: the scholar and his contributions to educational psychology. Educational psychology: A century of contributions. (pp. 431-457). Mahwah, NJ: Erlbaum.

Sobre os autores

Soely Polydoro é psicóloga, mestre em Psicologia Escolar pela Pontifícia Universidade Católica de Campinas e doutora em Educação pela Universidade Estadual de Campinas. É Professora do Departamento de Psicologia Escolar da Faculdade de Educação da UNICAMP. soelypolydoro@gmail.com

Daniela Couto Guerreiro Casanova é pedagoga, psicopedagoga, mestre e doutora em Educação pela Universidade Estadual de Campinas, pós-doutoranda em Políticas Educacionais pela Universidade Nove de Julho. danielaguerreiro@yahoo.com.br

Recebido em: 26/03/2015

Revisado em: 28/04/2015

Aceito em: $12 / 05 / 2015$ 